Published in final edited form as:

Curr Diab Rep. 2016 September ; 16(9): 87. doi:10.1007/s11892-016-0775-x.

\title{
Diabetes and Cognitive Impairment
}

\author{
Lindsay A. Zilliox ${ }^{1}$, Krish Chadrasekaran ${ }^{1}$, Justin Y. Kwan ${ }^{1}$, and James W. Russell, ${ }^{1,2}$ \\ ${ }^{1}$ Department of Neurology, Maryland VA Healthcare System and University of Maryland, 110 \\ South Paca Street, Baltimore, MD 21201, USA \\ ${ }^{2}$ School of Medicine, Department of Neurology, University of Maryland, 3S-129, 110 South Paca \\ Street, Baltimore, MD 21201-1595, USA
}

\begin{abstract}
Both type 1 (T1DM) and type 2 diabetes mellitus (T2DM) have been associated with reduced performance on multiple domains of cognitive function and with evidence of abnormal structural and functional brain magnetic resonance imaging (MRI). Cognitive deficits may occur at the very earliest stages of diabetes and are further exacerbated by the metabolic syndrome. The duration of diabetes and glycemic control may have an impact on the type and severity of cognitive impairment, but as yet we cannot predict who is at greatest risk of developing cognitive impairment. The patho-physiology of cognitive impairment is multifactorial, although dysfunction in each interconnecting pathway ultimately leads to discordance in metabolic signaling. The pathophysiology includes defects in insulin signaling, autonomic function, neuroinflammatory pathways, mitochondrial (Mt) metabolism, the sirtuin-peroxisome proliferator-activated receptorgamma co-activator 1a (SIRT-PGC-1a) axis, and Tau signaling. Several promising therapies have been identified in pre-clinical studies, but remain to be validated in clinical trials.
\end{abstract}

\section{Keywords}

Diabetes; Brain; Dementia; Encephalopathy; Neuropathy; Mitochondria; MRI; Treatment

\section{Introduction}

There is increasing evidence that diabetes predisposes to cognitive decline leading to dementia in both animal models and humans with both T1DM and T2DM [1-3]. Overall, the data shows a stronger association between dementia in T2DM than T1DM. Specifically, T2DM is associated with a $50 \%$ increase in the risk for dementia [2] and has been associated with impaired attention, processing and motor speed, executive functioning, and verbal memory $[1,4 \bullet \bullet, 5]$. Among the components of metabolic syndrome, hyperglycemia has the strongest association with the risk of developing cognitive impairment [6]. Diabetesrelated cognitive dysfunction can seriously challenge the demand for future health resources

Correspondence to: James W. Russell.

Compliance with Ethical Standards

Conflict of Interest The authors declare that they have no competing interests.

Human and Animal Rights and Informed Consent This article does not contain any studies with human or animal subjects performed by any of the authors. 
because of the increasing prevalence of T2DM and prolonged life-span. Thus, there is an urgent need to understand the pathophysiology of the disorder and to identify molecular targets and pathways that might lead to improved therapy in the future. Some of these targets and therapies are discussed in this review.

\section{Epidemiology}

It is estimated that there are 40 million people living with dementia worldwide and this number is expected to double every 20 years, to over 110 million in 2050 [7]. The most common type of dementia is Alzheimer's disease (AD), which accounts for at least $60 \%$ of all cases. Vascular dementia is the second most common dementing illness and has been estimated to account for approximately $20 \%$ of cases [8]. Diabetes in midlife is associated with a $19 \%$ greater cognitive decline over 20 years compared to those without diabetes [9]. The rising prevalence of diabetes mellitus worldwide is a public health concern largely due to the associated end organ complications. There are 415 million adults with diabetes mellitus worldwide and the number is projected to reach over 640 million by 2040 [10]. Diabetes mellitus is a significant risk factor for not only vascular dementia, but AD as well. Lifestyle risk factors for both vascular and nonvascular dementia include T2DM, cigarette smoking, and obesity.

A recent pooled analysis of 14 studies examined data from 2.3 million individuals and over 100,000 incident cases of dementia from cohorts from Asia, Europe, and the Americas [11]. It was found that diabetes was significantly associated with an approximately $60 \%$ increased risk of dementia. There was a $40 \%$ risk of nonvascular dementia. For vascular dementia, there was a stronger effect seen in women than in men. There was a $120 \%$ greater risk in women a $70 \%$ greater risk in men, which is an $18 \%$ excess risk in women with diabetes compared to men with diabetes.

It has been postulated that $\mathrm{AD}$ may represent the consequence of a distinct form of brainspecific insulin resistance and impaired glucose regulation [12, 13]. In 6370 elderly subjects studied for 2.1 years in the Rotterdam study, 126 subjects developed dementia and 89 had $\mathrm{AD}$ [14]. T2DM doubled the risk of a patient developing dementia (RR 1.9) and AD (RR 1.9). Patients taking insulin were at the highest risk of developing dementia with four times the risk [14]. Subjects with T2DM and impaired glucose tolerance (IGT) have an increased risk for cognitive impairment and dementia [14-16]. The severity of diabetes may be one risk factor for developing dementia [14]. However, individuals without diabetes that have higher average glucose levels also have an increased risk for dementia $(P=0.01)$ [17]. The adjusted hazard ratio for dementia in subjects with a minimally increased glucose level of $6.4 \mathrm{mmol}$ per liter is $1.18(1.04-1.33)$, suggesting that the elevated serum glucose level may be an independent risk factor [17]. Another study indicated that insulin resistance may have a more important role than an elevated fasting glucose level in increasing the risk for both mild cognitive impairment (MCI) and $\mathrm{AD}$ [18]. Obesity in midlife is another significant risk factor associated with dementia [19, 20]. In middle-overweight elderly women, a further increase in the body mass index by 1 point is associated with an increase in the AD risk by $36 \%$ [21]. The metabolic syndrome also increases the risk of dementia [6]. Thus overall, 
T2DM in midlife has a significant effect on the future risk for developing $\mathrm{AD}$ and in promoting the progression of $\mathrm{MCI}$ to $\mathrm{AD}[22,23]$.

\section{Clinical Effects of Diabetes on Cognition}

The best neuropsychological tests to evaluate impaired cognition in diabetes have not been established. The mini-mental state examination and the Montreal Cognitive Assessment (MOCA) are two screening tests that are often performed in a clinical setting. More in-depth and sensitive testing involves in-depth evaluation of multiple cognitive domains. Tests may evaluate more than one domain. Five commonly assessed cognitive domains include: abstract reasoning; memory, with the subdomains of working memory, immediate memory and learning rate, forgetting rate, and incidental memory; information processing speed; attention and executive function; and visuospatial skills. Abstract reasoning (for example, the Wisconsin Card Sorting Test) is the ability to conceptualize and to analyze information and recognize relationships and patterns in order to problem solve on an intangible level. Working memory (for example, the forward and backward digit span) allows one to hold and process information. Immediate memory is often referred to as short term memory and represents the ability to remember information for a short period of time, but not to manipulate the information. Immediate memory may be assessed by the Rey Auditory Verbal Learning Test (verbal memory) and the Location Learning Test (visual memory). Incidental memory (for example, the Taylor Complex Figure) is memory for information that people were not asked to remember. Information processing speed determined the efficiency of cognitive function. It is assessed by timed tasks such as the trail-making test and the stroop color-word test. Executive functions (for example, the trail-making, stroop color-word, letter fluency, and category fluency tests) are needed to analyze a situation, develop, and carry out a plan. Visuoconstruction refers to the ability to see an object or picture as a set of parts and the ability to construct a replica of the original from the parts. Visuospatial skills (for example, the Rey-Osterrieth Complex Figure test) are required for depth perception, recognizing surroundings and faces, locating objects and reading.

Several studies have showed deficits in different cognitive domains in diabetic patients. T2DM patient have reduced performance in information processing speed, and impaired memory, attention, and executive function [24-26]. Compared to matched controls, T2DM subjects had significantly lower scores in the trail-making test B $(p<0.004)$, color-word stroop test $(p<0.005)$, semantic fluency $(p<0.006)$, digit-symbol modalities test $(p<0.02)$, text recall from the Wechsler Memory Scale $(p<0.0001)$, Rey-Osterrieth Complex Figurecopy $(p<0.004)$, and delayed reproduction $(p<0.03)$.

Impaired executive function and memory is correlated with reduced gray matter density and reduced glucose metabolism in the orbital and prefrontal cortex, temporal cortex (middle gyrus, parahippocampus, and uncus), and cerebellar regions [27]. While both T1DM [28] and T2DM [28] are associated with impaired cognition, the current data suggests a stronger association with T2DM. Patients with T1DM have been found to have slower mental speed and reduced mental flexibility compared to non-diabetic controls [29]. These results have been interpreted as not suggesting an overall impairment of cognition but rather they are less able to flexibly acquire knowledge in new situations. A meta-analysis of 24 studies that 
included a total of over 26,000 patients (3351 with diabetes and 22,786 non-diabetic controls) found that individuals with T2DM performed worse on neurocognitive testing compared to non-diabetic controls. Patients with T2DM showed the greatest impairment in motor function, executive function, processing speed, verbal memory, and visual memory [5].

In T2DM patients, it is unclear when cognitive impairment occurs during the course of diabetes. Cognitive impairment may be a very early event and is shown to be present in individuals who have impaired fasting glucose [30]. Several longitudinal studies have examined the effect of T2DM on cognitive function over time. In the Utrecht Diabetic Encephalopathy Study, T2DM patients showed dysfunction in several frontal cognitive domains at baseline. Interestingly, these patients did not have an accelerated decline in cognitive function over time when compared to matched controls [26]. In contrast, another study showed a faster rate of cognitive decline in T2DM patients [31].

The ACCORD-MIND sub-study examined if the rate of cognitive decline in people with diabetes differed between those treated with standard of care compared to those treated under intensive care guidelines. Cross-sectional data from over 3000 patients with T2DM demonstrated an age-adjusted inverse relationship between cognitive function and A1C levels [32]. However, prospectively collected data found that total brain volumes were higher in the intensive treatment group but cognitive outcomes were not significantly different between the two groups $[33,34]$.

In T1DM patients, impairment in psychomotor speed, cognitive flexibility, visuospatial function, and attention have also been described [2]. Control of glycemic status and duration of disease may be risk factors for developing cognitive dysfunction. In the Diabetes Control and Complications Trial (DCCT) and the Epidemiology of Diabetes Interventions Complications (EDIC) study, T1DM patients who had higher glycosylated hemoglobin levels (HBA1C $>8.8 \%$ ) showed moderate declines in motor speed and psychomotor efficiency compared to patients who had better glycemic control (HBA1C < $7.4 \%$ ) [35]. Among children diagnosed with T1DM, greater cognitive impairment was present in children diagnosed under the age of 7 compared to children who were diagnosed at a later stage [36].

Patients who have metabolic syndrome are also at increased risk of developing cognitive dysfunction [6]. In the Longitudinal Aging Study Amsterdam, cognitive testing was performed to include general cognition (mini-mental state examination), memory (verbal learning test), fluid intelligence (Raven's Matrices), and information processing speed (coding task). In this cohort, $36.3 \%$ of the subjects had metabolic syndrome (US National Cholesterol Education Program definition) and abnormal cognitive testing was associated with metabolic syndrome and increased inflammatory markers. Hyperglycemia was the main contributor to the observed association of metabolic syndrome and cognition. 


\section{MRI Diagnosis of Structural and Functional Changes in the Diabetic Brain}

There is evidence of MRI abnormalities including a reduction in hippocampal volumes in both animal models [37•] and human subjects [33, 34, 38-40] with IGR. With improvement in glycemic control, there is stabilization of the rate of brain atrophy [33, 34]. Working memory (WM), which is a susceptible cognitive domain of mild cognitive impairment, and AD have been assessed in T2DM. Using a visual N-back task and functional (fMRI), patients with T2DM exhibited worse executive and memory abilities than control subjects [38]. Importantly, activation was more severely diminished in frontal cortex with increasing task difficulty and increased WM load [38].

Brain magnetic resonance spectroscopy (MRS) in diabetic brain also shows changes consistent with dementia. For example, ${ }^{1} \mathrm{H}$ MRS shows a significant difference in the hippocampal metabolic profile between LCR and HCR rats. ${ }^{1} \mathrm{H}$ MRS allows the noninvasive assessment of the altered brain metabolic profile associated with brain injury [41, 42]. In LCR compared to HCR rats, using a creatine and phosphocreatine $(\mathrm{Cr})$ internal standard, glutamate/tCr, myo-inositol $/ \mathrm{tCr}$, taurine $/ \mathrm{tCr}$, glycerophosphocholine, and phosphocholine/tCr ratios were significantly higher, whereas glutamine/tCr was reduced. There was no difference in the glucose/ $\mathrm{tCr}$ and $\mathrm{N}$-acetylaspartate (NAA)/tCr ratios [37•]. In human studies, the following general conclusions about impaired cognition in T2DM can be reached: NAA levels are mostly decreased, indicating loss of neuronal integrity; myoinositol levels are increased; excitatory neurotransmitters (glutamate and glycine) are increased; and inhibitory neurotransmitters (GABA) are decreased, consistent with abnormal pain regulation [43].

\section{Pathophysiology of Diabetes and Impaired Cognition}

\section{Insulin Signaling in the Brain}

Abnormalities in insulin signaling and insulin receptor (IR) sensitivity in the neuron and dendritic processes in $\mathrm{AD}$ have led to the hypothesis that metabolic dysfunction may be related to IR dysfunction (Fig. 1). IRs are expressed in the neuronal soma and more importantly in synaptic terminals that have a key role in preservation of memory in the hippocampus [44-46]. The source of insulin in the brain is uncertain and may originate from circulating insulin that crosses the blood brain barrier via a saturable transporter [47-49]. There is some evidence to suggest that insulin may be produced by the olfactory bulb and dentate gyrus and act in an autocrine fashion on the olfactory bulb and the hippocampus [50-52]. It is generally accepted that insulin signaling enhances memory and facilitates synaptic plasticity in the hippocampus, which has an important role in memory and learning. In the healthy mammalian brain, insulin facilitates hippocampal long-term potentiation (LTP), is associated with learning and memory, and increases the expression of N-methyl-Daspartate receptors [53]. Insulin also regulates the concentration of several neurotransmitters that have a role in memory formation, such as acetylcholine, norepinephrine and epinephrine [54], and promotes the accumulation of GABA(A) receptors to the post-synaptic membrane [55]. Although there are several lines of evidence supporting the importance of IR signaling in maintaining normal cognition, insulin treatment does not prevent the development of impaired cognitive function. Unlike its beneficial effects in a healthy brain [56, 57], 
increasing circulating insulin levels by insulin infusions does not improve memory function in cognitively impaired patients and may worsen certain memory tasks $[58,59]$.

\section{Mitochondria and Cognitive Function}

An important function of insulin in the brain is its role in regulating mitochondria (Mt) in the presynaptic hippocampus [60]. Amyloid beta can blunt the effect of insulin on synaptic terminal Mt and deplete the energy reserves required for synaptic plasticity, learning and memory [60] Similar to the proposal that there is reduced Mt function in AD, cognitive impairment may be partly due to cortical hypometabolism and a region-specific decline in glucose utilization and impaired insulin signaling (Fig. 2). Interestingly, inhibitors of Mt bioenergetics produce a pattern of metabolic changes that mimics that observed in brains of $\mathrm{AD}$ patients [37•,61], supporting the critical role of $\mathrm{Mt}$ in normal cognitive function. This decline in Mt function is associated with epigenetic silencing of nuclear or Mt DNA and failure of DNA repair that can result in neuronal failure [62]. Accumulation of mutations in Mt DNA and reduced Mt proteins causes functional and structural changes in the Mt [63, 64] and may manifest as a reduction in transcription for components of the Mt electron transport chain (e.g., complex I and III) or regulators of Mt bioenergetics [65]. The consequence of these alterations in the Mt is neuronal synaptic dysfunction and loss that correlates with cognitive deficits in $\mathrm{AD}$.

Tau is the most commonly found microtubule-associated protein in the human brain and phosphorylated tau is suggested to have an important role in synaptic plasticity during development [37•]. In AD, tau becomes abnormally hyperphosphorylated (p-tau) and biochemically modified by other mechanisms resulting in an increased tendency for tau to polymerize and form intraneuronal paired helical filament (PHF) tau protein. PHF-tau protein is the main component of neurofibrillary tangles, an intracytoplasmic neuronal inclusion consistently seen in AD. p-Tau is also found in the hippocampus of animal models of T1DM and T2DM [66]. A recent important observation is that p-tau is specifically present in the hippocampal Mt of low-capacity running (LCR) rats, a model of obesity, hyperinsulinemia, memory and Mt impairment [37•]. In the aged LCR rat hippocampus neurons, there was an increase in p-tau in the microtubule-associated protein but not in age and gender matched high capacity running (HCR) rat hippocampal neurons [37•]. Compared to HCR rats, the LCR rat hippocampal neurons also showed decreased Mt respiratory chain complex III activity. Respiratory chain complex I, II, or IV remained unchanged in the LCR animals [37•]. In the triple transgenic mouse model (pR5/APP/PS2)-triple AD mice, there is altered Mt function mainly related to modification of Mt complexes I and IV activity [67]. However, the exact molecular mechanism by which p-tau disrupts ATP synthesis and cell bioenergetics is unknown.

Downregulation of proteins that participate in normal Mt function is another mechanism that may result in impaired neuronal Mt function. The 35-kDa PGC-1a binds and colocalizes with PTEN-induced putative kinase 1 (PINK1) in brain Mt and is suggested to have a role in regulating Mt function $[68,69]$. Decreased PGC-1a and PINK1 is associated with increased production of oxygen species (ROS) and decreased protein levels of key Mt $\beta$-oxidation enzymes. PINK1 immunoreactivity is observed in senile plaques, vascular amyloid 
deposition, and reactive astrocytes associated with the $\mathrm{AD}$ lesions. This suggests upregulation of PINK1 as a possible protective mechanism in AD [70]. Downregulation of PGC-1 $\alpha$ in transgenic mice results in Mt dysfunction and spongiform brain pathology [71, 72]. PGC-1a and PINK1 expression is significantly decreased in human AD hippocampus and in mouse diabetic hippocampus [69] supporting the hypothesis that Mt dysfunction may be a shared mechanism in both disorders. Upregulation of PGC-1a increases Mt fatty acid oxidation by a PINK1-dependent mechanism, consistent with the concept that PGC-1 $a$ is an important therapeutic target.

Recent data indicates that another molecule linking dementia with Mt metabolism is Sirtuin 1 (SIRT1). SIRT1 is an $\mathrm{NAD}^{+}$-dependent protein deacetylase that catalyzes the removal of acetyl groups from lysine residues in substrate proteins. SIRT1 deacetylates PGC-1a, FOXO, Nuclear factor kappa-light-chain-enhancer of activated B cells (NF-kB), and consequently promotes Mt oxidative metabolism and reduces reactive ROS generation. Furthermore, Mt biogenesis is regulated by the SIRT1-PGC-1a axis and this would be critical in $\mathrm{AD}$ where Mt show structural and functional abnormalities. Another important hallmark of $\mathrm{AD}$ is the presence of reactive gliosis, which can be prevented by SIRT1 activators that also reduce production of pro-inflammatory mediators [73]. Thus, $\mathrm{NAD}^{+}$ precursors such as nicotinamide riboside or other SIRT1 activators could have a therapeutic role in treating dementia.

\section{Diabetic Autonomic Dysfunction and Cognitive Impairment}

Diabetic autonomic neuropathy (DAN) is a common complication of diabetes, but its pathogenesis remains poorly understood and it is typically unrecognized. DAN is associated with poor hypertension control and increased risk for stroke, which are both risk factors for cognitive impairment. However, there is limited evidence to suggest a relationship between DAN and cognitive dysfunction. Patients who have T2DM and autonomic neuropathy have been shown to have poorer performance on cognitive tests of visual memory compared to diabetic patients without DAN and non-diabetic patients [74]. There was no difference in verbal memory performance. Diabetic subjects with DAN did have a higher frequency of retinopathy and microangiopathy even after controlling for potential confounders. This raises the possibility that DAN may reflect abnormalities in autonomic centers in the hypothalamus, midbrain, brainstem and cortex. There are three prevailing hypotheses supporting the association between autonomic dysfunction and cognitive impairment. First, in neurodegenerative conditions, orthostatic hypotension and cognitive impairment may be due to a common pathologic process affecting areas in the central nervous system that have a role in cognition and autonomic control. The second hypothesis is that orthostatic hypotension may cause cerebral hypoperfusion which has been shown to play a role in causing or exacerbating cognitive impairment. The third hypothesis is that cognitive impairment may be a transient symptom of orthostatic hypotension rather than a chronic effect.

The hypothesis that cognitive impairment and autonomic dysfunction may share a common underlying pathologic mechanism originates from the observation that impaired autonomic function is present in patients with several different types of dementia (mild cognitive 
impairment, $\mathrm{AD}$, frontotemporal dementia, dementia with Lewy bodies, and Parkinson disease with dementia). In patients with mild cognitive impairment, there is evidence of sympathetic cardiac autonomic dysfunction compared to age-matched controls with normal cognition [75•]. The finding of preferential impairment of sympathetic function has led to the proposed idea that there may be damage to the right insula because the insula plays a key role in cognitive function and regulation of the autonomic nervous system [76]. Orthostatic hypotension is more common in older people. This is thought to be due to "stiffening" of the arterial system and a decline in the sensitivity of baroreceptors causing reduced cerebral autoregulation, which is needed to maintain proper cerebral blood flow. Abrupt changes in blood pressure due to dysautonomia can further exacerbate changes in cerebral blood flow, which is associated with cognitive dysfunction. Orthostatic hypotension and blood pressure dysregulation is associated with white matter lesions on brain imaging, silent cerebral infarcts, and the accumulated brain injury predicts the likelihood and rate of future cognitive decline [77]. The association between blood pressure dysregulation, silent cerebral infarcts and cognitive decline suggests that chronic intermittent reductions in cerebral blood flow secondary to increased blood pressure fluctuations may contribute to the development of cognitive impairment. In fact, the effects of blood pressure fluctuations on cognition may occur prior to the development of orthostatic hypotension. A large cross-sectional study of people over 50 years found that a reduced heart rate variability, a sign of impaired cardiovagal autonomic function, had a significant association with lower cognitive performance [77]. The transient effects of autonomic dysfunction on cognition come from studies of patients with peripheral autonomic disorders. Patients who have pure autonomic failure or an autoimmune autonomic neuropathy have been found to have a normal cognitive evaluation while sitting, but they perform significantly worse on tests of executive function during tilt table testing when compared to healthy controls [78]. The observed cognitive deficits that occur during tilt table testing may be due to transient cerebral hypoperfusion. In support of this hypothesis, imaging studies have showed decreased cerebral blood flow in frontal areas in patients who have pure autonomic failure. Similarly, in autoimmune autonomic ganglionopathy, orthostatic hypotension was found to be independently associated with neuropsychological impairment [79]. This study found improvement in cognitive scores after treatment with plasmapheresis in both upright and seated positions corresponding to improvement in the autonomic neuropathy.

\section{Neuroinflammation and the Diabetic Brain}

In diabetes, there is an increase in the expression of pro-inflammatory cytokines in the brain under diabetic conditions and this plays an important role in neuronal damage [80••]. NF-kB has been postulated to be involved in cognitive function. BAY 11-7082 (BAY) is a pharmacological inhibitor of $\mathrm{IkBa}$ (inhibitor of kappa $\mathrm{B}$ alpha) phosphorylation that blocks NF-kB activation and decreases interleukin-6 (IL-6) and tumor necrosis factor (TNF) levels. In T2DM rats, BAY improved learning and memory performance without affecting glycemic control [81]. In diabetic human postmortem hippocampus, there is similar activation of microglia to that observed in patients with AD [82]. High-fat-diet-fed mice have increased TNF levels and microglia/macrophage activation in the brain consistent with proinflammatory changes in the brain [83]. Diabetic and obese $\mathrm{db} / \mathrm{db}$ mice $(\mathrm{db} / \mathrm{db})$ display impaired spatial-recognition memory, which is associated with increased levels of pro- 
inflammatory cytokines (IL-1 $\beta$, TNF, and IL-6), suggesting an interaction between inflammation and memory impairment [84]. Neuroinflammation and oxidative stress are also linked. Generation of ROS in the diabetic brain activates multiple cellular pathways including advanced glycation end products (AGE/RAGE), polyol, and protein kinase C (PKC) pathways, leading to increased brain inflammation and neurodegeneration [85]. NF$\mathrm{kB}$ is also a modulator of ROS and regulates the expression of TNF and interleukins, playing a major role in the initiation of the inflammatory cascade. Upregulation of TNF also inhibits insulin signaling leading to increased ROS generation and cognitive impairment [37•, 8688].

\section{Therapeutic Interventions in the Diabetic Brain}

\section{Exercise and the Diabetic Brain}

Recent studies including, "The Study of Mental and Resistance Training (SMART) study", showed convincingly that exercise interventions were effective in reducing MCI $[89,90]$. However, a meta-analysis of available data concluded that many previous studies had not shown significant improvement with exercise in older adults with MCI [91]. There is far less information evaluating lifestyle intervention in subjects with IGR. A pilot study with less than 20 subjects examined the effects of a 24-week exercise intervention program on cognitive function in adults with T2DM [92]. Measures of cognitive performance declined following the intervention, however there were several problems with the study. In addition to the obvious small number of subjects, the metabolic parameters generally worsened after the intervention, which questions the effectiveness of the intervention. The pilot study also lacked a control group for the intervention. In a carefully conducted study comprising subjects with T2DM, IGT, and IFG, there was improvement in executive function after a 6 month aerobic intervention when compared to a stretching control group [93]. Subjects were only supervised for the first 8 weeks of the intervention, and there was a disproportionately greater number of women than men. Another study in Japanese Americans with IGT showed improvement in verbal memory after an exercise and dietary intervention for 6 months [94].

\section{Other Potential Therapies}

As with diabetic neuropathy and T2DM, the effect of improved glycemic control is uncertain. In The Memory in Diabetes (ACCORD-MIND) study, there was slowing in the rate of brain atrophy on MRI in patients with T2DM receiving intensive glycemic control compared with those receiving standard therapy. However, this was not accompanied by improved cognitive function [33, 34]. Clearly, glycemic level has little impact on neurological function in T2DM [33, 34, 95]. In contrast, insulin therapy by the intranasal route may be more promising for improving cognition in T1DM [96]. Insulin reduces intracellular amyloid plaque, promotes tau hypophosphorylation, which stabilizes microtubules, and promotes tubulin polymerization [96].

There has also been interest in testing other antidiabetic drugs to treat cognitive impairment. For example, long-lived mimetics of the glucagon-like peptide-1 (GLP-1), which are resistant to cleavage by proteases, affect key pathophysiological pathways that may prevent development of memory impairment in animal models of diabetes and AD [97-99]. 
Liraglutide reduced memory impairment and increased synaptic plasticity in the amyloid precursor protein (APP)/presenilin 1 (PS1) mouse model of AD [100]. Both liraglutide and a newer GLP-1 analog, lixisenatide, reversed memory impairment in object recognition and water maze tasks, prevented synapse loss and deterioration of synaptic plasticity in the hippocampus, reduced beta-amyloid plaque count in the cortex, and dense-core plaque numbers in old transgenic AD mice [99, 100]. GLP-1 analogs that are being assessed for treatment of $\mathrm{AD}$ in human pilot studies include exendin-4 (Clinicaltrials.gov identifier:NCT01255163) and liraglutide (ClinicalTrials.gov identifier: NCT01843075). The limitation of GLP-1 is that while it facilitates insulin release from the pancreas, its short half-life is a limitation for therapeutic use. Thus, long-acting GLP-1 receptor (GLP-1R) agonists and dipeptidyl peptidase-4 (DPP-4) inhibitors have been developed as treatments for T2DM. These drugs have the therapeutic benefit of increasing insulin secretion and decreasing glucagon production in a glucose-dependent manner without promoting hypoglycemia. Vildagliptin and sitagliptin (DPP-4 inhibitors) increase brain GLP-1 levels, neuronal insulin receptor phosphorylation, restore brain Mt function, and attenuate high fat induced cognitive impairment [101, 102]. Human clinical trials with other GLP-1 analogs and other antidiabetic medications, such as rosiglitazone and pioglitazone, have also recently been completed but data is not currently reported.

Finally, other medications such as anti-oxidants and anti-inflammatory therapies have shown promise in animal models. Anti-oxidants and anti-inflammatory medications such as 3,4methylenedioxyphenol (Sesamol), curcumin, and vitamin E significantly improve learning and memory performance in STZ rats, can reduce inflammatory markers, can reverse lipid peroxidation, and normalize glutathione levels [103-105].

\section{Conclusions}

In both T1DM and T2DM, there are mild to moderate deficits in cognitive function that may be more severely manifest in T2DM where there is concomitant metabolic syndrome. MRI/ fMRI and MRS show great promise in evaluating structural, functional, and metabolic changes in the brain and correlating these in real-time with cognitive deficits to identify critical cerebral impairments and response to therapy. The pathophysiology of diabetic cognitive impairment is complex but is likely to involve impaired insulin signaling, increased inflammatory and oxidative stress pathways, and defects in Mt metabolism and regulation. Identifying key pathophysiological components is vital to developing new approaches to therapy. In T2DM, lifestyle interventions that couple aerobic exercise with tailored dietary interventions currently offer the most likely benefit. Even here, the literature showing that a lifestyle intervention improves cognition and the brain MRI in T2DM is controversial. Furthermore, any improvement does not seem to be linked to glycemic control in T2DM [33, 34]. Other therapies that improve insulin signaling or sensitivity may also offer benefit and trials with GLP-1 mimetics are currently active. Other therapies including anti-oxidants and anti-inflammatory medications are effective in animal models. However, the early promise of pre-clinical studies remains to be translated into evidence of benefit in human clinical trials. 


\section{Acknowledgments}

Supported in part by the Office of Research Development (R\&D), Department of Veterans Affairs (LZ); Office of Research Development, Department of Veterans Affairs (Biomemedical and Laboratory Research Service and Rehabilitation Research and Development, 101RX001030), National Institute of Diabetes and Digestive and Kidney Diseases, National Institutes of Health 1R01DK107007-01A1, Diabetes Action Research and Education Foundation (JWR), and grant P30DK072488 from the National Institute of Diabetes and Digestive and Kidney Diseases.

\section{References}

Papers of particular interest, published recently, have been highlighted as:

- Of importance

•• Of major importance

1. Wong RH, Scholey A, Howe PR. Assessing premorbid cognitive ability in adults with type 2 diabetes mellitus - a review with implications for future intervention studies. Curr Diab Rep. 2014; 14(11):547-0547. [PubMed: 25273482]

2. Biessels GJ, Staekenborg S, Brunner E, Brayne C, Scheltens P. Risk of dementia in diabetes mellitus: a systematic review. Lancet Neurol. 2006; 5(1):64-74. [PubMed: 16361024]

3. Grunblatt E, Bartl J, Riederer P. The link between iron, metabolic syndrome, and Alzheimer's disease. J Neural Transm. 2010; 118(3):371-79. [PubMed: 20556444]

4••. Monette MC, Baird A, Jackson DL. A meta-analysis of cognitive functioning in nondemented adults with type 2 diabetes mellitus. Can J Diabetes. 2014; 38(6):401-8. This study examines the pattern and magnitude of cognitive functioning deficits in persons withT2DM without dementia using meta-analysis. [PubMed: 24933107]

5. Palta P, Schneider AL, Biessels GJ, Touradji P, Hill-Briggs F. Magnitude of cognitive dysfunction in adults with type 2 diabetes: a meta-analysis of six cognitive domains and the most frequently reported neuropsychological tests within domains. J Int Neuropsychol Soc. 2014; 20(3):278-91. [PubMed: 24555960]

6. Dik MG, Jonker C, Comijs HC, Deeg DJ, Kok A, Yaffe K, et al. Contribution of metabolic syndrome components to cognition in older individuals. Diabetes Care. 2007; 30(10):2655-60. [PubMed: 17563341]

7. Prince M, Bryce R, Albanese E, Wimo A, Ribeiro W, Ferri CP. The global prevalence of dementia: a systematic review and metaanalysis. Alzheimers Dement. 2013; 9(1):63-75. [PubMed: 23305823]

8. Rizzi L, Rosset I, Roriz-Cruz M. Global epidemiology of dementia: Alzheimer's and vascular types. Biomed Res Int. 2014; 2014:908915.doi: 10.1155/2014/908915 [PubMed: 25089278]

9. Rawlings AM, Sharrett AR, Schneider AL, Coresh J, Albert M, Couper D, et al. Diabetes in midlife and cognitive change over 20 years: a cohort study. Ann Intern Med. 2014; 161(11):785-93. [PubMed: 25437406]

10. International Diabetes Federation. IDF diabetes atlas. 7. Brussels: International Diabetes Federation; 2015. http://www.diabetesatlas.org

11. Chatterjee S, Peters SA, Woodward M, Mejia AS, Batty GD, Beckett N, et al. Type 2 diabetes as a risk factor for dementia in women compared with men: a pooled analysis of 2.3 million people comprising more than 100,000 cases of dementia. Diabetes Care. 2016; 39(2):300-7. [PubMed: 26681727]

12. de la Monte SM. Brain insulin resistance and deficiency as therapeutic targets in Alzheimer's disease. Curr Alzheimer Res. 2012; 9(1):35-66. [PubMed: 22329651]

13. Akter K, Lanza EA, Martin SA, Myronyuk N, Rua M, Raffa RB. Diabetes mellitus and Alzheimer's disease: shared pathology and treatment? Br J Clin Pharmacol. 2011; 71(3):365-76. [PubMed: 21284695]

14. Ott A, Stolk RP, van Harskamp F, Pols HA, Hofman A, Breteler MM. Diabetes mellitus and the risk of dementia: The Rotterdam Study. Neurology. 1999; 53(9):1937-42. [PubMed: 10599761] 
15. Luchsinger JA. Adiposity, hyperinsulinemia, diabetes and Alzheimer's disease: an epidemiological perspective. Eur J Pharmacol. 2008; 585(1):119-29. [PubMed: 18384771]

16. Karan NS. Assessment of the cognitive status in diabetes mellitus. J Clin Diagn Res. 2012; 6(10): 1658-62. [PubMed: 23373022]

17. Crane PK, Walker R, Hubbard RA, Li G, Nathan DM, Zheng H, et al. Glucose levels and risk of dementia. N Engl J Med. 2013; 369(6):540-8. [PubMed: 23924004]

18. Ohara T, Doi Y, Ninomiya T, Hirakawa Y, Hata J, Iwaki T, et al. Glucose tolerance status and risk of dementia in the community: the Hisayama study. Neurology. 2011; 77(12):1126-34. [PubMed: 21931106]

19. Whitmer RA. Type 2 diabetes and risk of cognitive impairment and dementia. Curr Neurol Neurosci Rep. 2007; 7(5):373-80. [PubMed: 17764626]

20. Whitmer RA. The epidemiology of adiposity and dementia. Curr Alzheimer Res. 2007; 4(2):11722. [PubMed: 17430233]

21. Gustafson D, Rothenberg E, Blennow K, Steen B, Skoog I. An 18-year follow-up of overweight and risk of Alzheimer disease. Arch Intern Med. 2003; 163(13):1524-8. [PubMed: 12860573]

22. Schnaider BM, Goldbourt U, Silverman JM, Noy S, Schmeidler J, Ravona-Springer R, et al. Diabetes mellitus in midlife and the risk of dementia three decades later. Neurology. 2004; 63(10): 1902-7. [PubMed: 15557509]

23. Xu W, Caracciolo B, Wang HX, Winblad B, Backman L, Qiu C, et al. Accelerated progression from mild cognitive impairment to dementia in people with diabetes. Diabetes. 2010; 59(11): 2928-35. [PubMed: 20713684]

24. Kanaya AM, Barrett-Connor E, Gildengorin G, Yaffe K. Change in cognitive function by glucose tolerance status in older adults: a 4-year prospective study of the Rancho Bernardo study cohort. Arch Intern Med. 2004; 164(12):1327-33. [PubMed: 15226167]

25. Gregg EW, Yaffe K, Cauley JA, Rolka DB, Blackwell TL, Narayan KM, et al. Is diabetes associated with cognitive impairment and cognitive decline among older women? Study of Osteoporotic Fractures Research Group. Arch Intern Med. 2000; 160(2):174-80. [PubMed: 10647755]

26. van den Berg E, Reijmer YD, de Bresser J, Kessels RP, Kappelle LJ, Biessels GJ. A 4 year followup study of cognitive functioning in patients with type 2 diabetes mellitus. Diabetologia. 2010; 53(1):58-65. [PubMed: 19882137]

27. Garcia-Casares N, Jorge RE, Garcia-Arnes JA, Acion L, Berthier ML, Gonzalez-Alegre P, et al. Cognitive dysfunctions in middle-aged type 2 diabetic patients and neuroimaging correlations: a cross-sectional study. J Alzheimers Dis. 2014; 42(4):1337-46. [PubMed: 25024335]

28. Moheet A, Mangia S, Seaquist ER. Impact of diabetes on cognitive function and brain structure. Ann N Y Acad Sci. 2015; 1353:60-71. DOI: 10.1111/nyas.12807 [PubMed: 26132277]

29. Brands AM, Biessels GJ, de Haan EH, Kappelle LJ, Kessels RP. The effects of type 1 diabetes on cognitive performance: a meta-analysis. Diabetes Care. 2005; 28(3):726-35. [PubMed: 15735218]

30. Yaffe K, Blackwell T, Kanaya AM, Davidowitz N, Barrett-Connor E, Krueger K. Diabetes, impaired fasting glucose, and development of cognitive impairment in older women. Neurology. 2004; 63(4):658-63. [PubMed: 15326238]

31. Hassing LB, Grant MD, Hofer SM, Pedersen NL, Nilsson SE, Berg S, et al. Type 2 diabetes mellitus contributes to cognitive decline in old age: a longitudinal population-based study. J Int Neuropsychol Soc. 2004; 10(4):599-607. [PubMed: 15327738]

32. Cukierman-Yaffe T, Gerstein HC, Williamson JD, Lazar RM, Lovato L, Miller ME, et al. Relationship between baseline glycemic control and cognitive function in individuals with type 2 diabetes and other cardiovascular risk factors: the action to control cardiovascular risk in diabetesmemory in diabetes (ACCORD-MIND) trial. Diabetes Care. 2009; 32(2):221-6. [PubMed: 19171735]

33. Launer LJ, Miller ME, Williamson JD, Lazar RM, Gerstein HC, Murray AM, et al. Effects of intensive glucose lowering on brain structure and function in people with type 2 diabetes (ACCORD MIND): a randomised open-label substudy. Lancet Neurol. 2011; 10(11):969-77. [PubMed: 21958949] 
34. Erus G, Battapady H, Zhang T, Lovato J, Miller ME, Williamson JD, et al. Spatial patterns of structural brain changes in type 2 diabetic patients and their longitudinal progression with intensive control of blood glucose. Diabetes Care. 2015; 38(1):97-104. [PubMed: 25336747]

35. Jacobson AM, Musen G, Ryan CM, Silvers N, Cleary P, Waberski B, et al. Long-term effect of diabetes and its treatment on cognitive function. N Engl J Med. 2007; 356(18):1842-52. [PubMed: 17476010]

36. Gaudieri PA, Chen R, Greer TF, Holmes CS. Cognitive function in children with type 1 diabetes: a meta-analysis. Diabetes Care. 2008; 31(9):1892-7. [PubMed: 18753668]

37•. Choi J, Chandrasekaran K, Demarest TG, Kristian T, Xu S, Vijaykumar K, et al. Brain diabetic neurodegeneration segregates with low intrinsic aerobic capacity. Ann Clin Transl Neurol. 2014; 1(8):589-604. This paper links mitochondrial p-tau hyperphosphorylation, a marker of AD, with mitochondrial dysfunction in the hippocampus in a rat model of T2DM. [PubMed: 25356430]

38. Chen Y, Liu Z, Zhang J, Xu K, Zhang S, Wei D, et al. Altered brain activation patterns under different working memory loads in patients with type 2 diabetes. Diabetes Care. 2014; 37(12): 3157-63. [PubMed: 25404661]

39. Cherbuin N, Sachdev P, Anstey KJ. Higher normal fasting plasma glucose is associated with hippocampal atrophy: The PATH Study. Neurology. 2012; 79(10):1019-26. [PubMed: 22946113]

40. Biessels GJ, Reijmer YD. Brain changes underlying cognitive dysfunction in diabetes: what can we learn from MRI? Diabetes. 2014; 63(7):2244-52. [PubMed: 24931032]

41. Marjanska M, Curran GL, Wengenack TM, Henry PG, Bliss RL, Poduslo JF, et al. Monitoring disease progression in transgenic mouse models of Alzheimer's disease with proton magnetic resonance spectroscopy. Proc Natl Acad Sci U S A. 2005; 102(33):11906-10. [PubMed: 16091461]

42. Xu S, Zhuo J, Racz J, Shi D, Roys S, Fiskum G, et al. Early microstructural and metabolic changes following controlled cortical impact injury in rat: a magnetic resonance imaging and spectroscopy study. J Neurotrauma. 2011; 28(10):2091-102. [PubMed: 21761962]

43. Santhakumari R, Reddy IY, Archana R. Effect of type 2 diabetes mellitus on brain metabolites by using proton magnetic resonance spectroscopy a systematic review. Int J Pharma Bio Sci. 2014; 5(4):1118-23.

44. Abbott MA, Wells DG, Fallon JR. The insulin receptor tyrosine kinase substrate p58/53 and the insulin receptor are components of CNS synapses. J Neurosci. 1999; 19(17):7300-8. [PubMed: 10460236]

45. Werther GA, Hogg A, Oldfield BJ, McKinley MJ, Figdor R, Mendelsohn FA. Localization and characterization of Insulin-Like Growth Factor-I Receptors in rat brain and pituitary gland using in vitro autoradiography and computerized densitometry* a distinct distribution from insulin receptors. J Neuroendocrinol. 1989; 1(5):369-77. [PubMed: 19210430]

46. Zhao W, Chen H, Xu H, Moore E, Meiri N, Quon MJ, et al. Brain insulin receptors and spatial memory. Correlated changes in gene expression, tyrosine phosphorylation, and signaling molecules in the hippocampus of water maze trained rats. J Biol Chem. 1999; 274(49):34893-902. [PubMed: 10574963]

47. Baskin DG, Figlewicz DP, Woods SC, Porte D Jr, Dorsa DM. Insulin in the brain. Annu Rev Physiol. 1987; 49:335-47. [PubMed: 3551804]

48. Banks WA, Owen JB, Erickson MA. Insulin in the brain: there and back again. Pharmacol Ther. 2012; 136(1):82-93. [PubMed: 22820012]

49. Woods SC, Seeley RJ, Baskin DG, Schwartz MW. Insulin and the blood-brain barrier. Curr Pharm Des. 2003; 9(10):795-800. [PubMed: 12678878]

50. Devaskar SU, Giddings SJ, Rajakumar PA, Carnaghi LR, Menon RK, Zahm DS. Insulin gene expression and insulin synthesis in mammalian neuronal cells. J Biol Chem. 1994; 269(11):844554. [PubMed: 8132571]

51. Devaskar SU, Singh BS, Carnaghi LR, Rajakumar PA, Giddings SJ. Insulin II gene expression in rat central nervous system. Regul Pept. 1993; 48:55-63. [PubMed: 8265817]

52. Kuwabara T, Kagalwala MN, Onuma Y, Ito Y, Warashina M, Terashima K, et al. Insulin biosynthesis in neuronal progenitors derived from adult hippocampus and the olfactory bulb. EMBO Mol Med. 2011; 3(12):742-54. [PubMed: 21984534] 
53. Skeberdis VA, Lan J, Zheng X, Zukin RS, Bennett MV. Insulin promotes rapid delivery of Nmethyl-D- aspartate receptors to the cell surface by exocytosis. Proc Natl Acad Sci U S A. 2001; 98(6):3561-6. [PubMed: 11248117]

54. Boyd FT Jr, Clarke DW, Muther TF, Raizada MK. Insulin receptors and insulin modulation of norepinephrine uptake in neuronal cultures from rat brain. J Biol Chem. 1985; 260(29):15880-4. [PubMed: 3905797]

55. Wan Q, Xiong ZG, Man HY, Ackerley CA, Braunton J, Lu WY, et al. Recruitment of functional GABA(A) receptors to postsynaptic domains by insulin. Nature. 1997; 388(6643):686-90. [PubMed: 9262404]

56. Marks DR, Tucker K, Cavallin MA, Mast TG, Fadool DA. Awake intranasal insulin delivery modifies protein complexes and alters memory, anxiety, and olfactory behaviors. J Neurosci. 2009; 29(20):6734-51. [PubMed: 19458242]

57. Shemesh E, Rudich A, Harman-Boehm I, Cukierman-Yaffe T. Effect of intranasal insulin on cognitive function: a systematic review. J Clin Endocrinol Metab. 2012; 97(2):366-76. [PubMed: 22162476]

58. Morris JK, Vidoni ED, Mahnken JD, Montgomery RN, Johnson DK, Thyfault JP, et al. Cognitively impaired elderly exhibit insulin resistance and no memory improvement with infused insulin. Neurobiol Aging. 2016; 39:19-24. DOI: 10.1016/j.neurobiolaging.2015.11.005 [PubMed: 26923398]

59. Calvo-Ochoa E, Arias C. Cellular and metabolic alterations in the hippocampus caused by insulin signalling dysfunction and its association with cognitive impairment during aging and Alzheimer's disease: studies in animal models. Diabetes Metab Res Rev. 2015; 31(1):1-13.

60. Heras-Sandoval D, Ferrera P, Arias C. Amyloid-beta protein modulates insulin signaling in presynaptic terminals. Neurochem Res. 2012; 37(9):1879-85. [PubMed: 22638775]

61. Choi J, Malakowsky CA, Talent JM, Conrad CC, Gracy RW. Identification of oxidized plasma proteins in Alzheimer's disease. Biochem Biophys Res Commun. 2002; 293(5):1566-70. [PubMed: 12054695]

62. Lu T, Pan Y, Kao SY, Li C, Kohane I, Chan J, et al. Gene regulation and DNA damage in the ageing human brain. Nature. 2004; 429(6994):883-91. [PubMed: 15190254]

63. Wang X, Su B, Lee HG, Li X, Perry G, Smith MA, et al. Impaired balance of mitochondrial fission and fusion in Alzheimer's disease. J Neurosci. 2009; 29(28):9090-103. [PubMed: 19605646]

64. Su B, Wang X, Zheng L, Perry G, Smith MA, Zhu X. Abnormal mitochondrial dynamics and neurodegenerative diseases. Biochim Biophys Acta. 2010; 1802(1):135-42. [PubMed: 19799998]

65. Chandrasekaran K, Hatanpaa K, Rapoport SI, Brady DR. Decreased expression of nuclear and mitochondrial DNA-encoded genes of oxidative phosphorylation in association neo-cortex in Alzheimer disease. Brain Res Mol Brain Res. 1997; 44(1):99-104. [PubMed: 9030703]

66. Kim B, Backus C, Oh S, Hayes JM, Feldman EL. Increased tau phosphorylation and cleavage in mouse models of type 1 and type 2 diabetes. Endocrinology. 2009; 150(12):5294-301. [PubMed: 19819959]

67. Eckert A, Schulz KL, Rhein V, Gotz J. Convergence of amyloid-beta and tau pathologies on mitochondria in vivo. Mol Neurobiol. 2010; 41(2-3):107-14. [PubMed: 20217279]

68. Choi J, Batchu VV, Schubert M, Castellani RJ, Russell JW. A novel PGC-1alpha isoform in brain localizes to mitochondria and associates with PINK1 and VDAC. Biochem Biophys Res Commun. 2013; 435(4):671-7. [PubMed: 23688429]

69. Choi J, Ravipati A, Nimmagadda V, Schubert M, Castellani RJ, Russell JW. Potential roles of PINK1 for increased PGC-1alpha-mediated mitochondrial fatty acid oxidation and their associations with Alzheimer disease and diabetes. Mitochondrion. 2014; 18:41-8. DOI: 10.1016/ j.mito.2014.09.005 [PubMed: 25260493]

70. Wilhelmus MM, van der Pol SM, Jansen Q, Witte ME, van der Valk P, Rozemuller AJ, et al. Association of Parkinson disease-related protein PINK1 with Alzheimer disease and multiple sclerosis brain lesions. Free Radic Biol Med. 2011; 50(3):469-76. [PubMed: 21145388]

71. Choi J, Chandrasekaran K, Inoue T, Muragundla A, Russell JW. PGC-1alpha regulation of mitochondrial degeneration in experimental diabetic neuropathy. Neurobiol Dis. 2014; 64:118-30. [PubMed: 24423644] 
72. Lin J, Wu PH, Tarr PT, Lindenberg KS, St Pierre J, Zhang CY, et al. Defects in adaptive energy metabolism with CNS-linked hyperactivity in PGC-1alpha null mice.[see comment]. Cell. 2004; 119(1):125-35.

73. Scuderi C, Stecca C, Bronzuoli MR, Rotili D, Valente S, Mai A, et al. Sirtuin modulators control reactive gliosis in an in vitro model of Alzheimer's disease. Front Pharmacol. 2014; 5:89. eCollection: 2014. doi: 10.3389/fphar.2014.00089 [PubMed: 24860504]

74. Zaslavsky LM, Gross JL, Chaves ML, Machado R. Memory dysfunction and autonomic neuropathy in non-insulin-dependent (type 2) diabetic patients. Diabetes Res Clin Pract. 1995; 30(2):101-10. [PubMed: 8833630]

75•. Nicolini P, Ciulla MM, Malfatto G, Abbate C, Mari D, Rossi PD, et al. Autonomic dysfunction in mild cognitive impairment: evidence from power spectral analysis of heart rate variability in a cross-sectional case-control study. PLoS One. 2014; 9(5):e96656. The study links autonomic dysfunction with presence of MCI. [PubMed: 24801520]

76. Seeley WW. Anterior insula degeneration in frontotemporal dementia. Brain Struct Funct. 2010; 214(5-6):465-75. [PubMed: 20512369]

77. Frewen J, Finucane C, Savva GM, Boyle G, Coen RF, Kenny RA. Cognitive function is associated with impaired heart rate variability in ageing adults: the Irish longitudinal study on ageing wave one results. Clin Auton Res. 2013; 23(6):313-23. [PubMed: 24077752]

78. Guaraldi P, Poda R, Calandra-Buonaura G, Solieri L, Sambati L, Gallassi R, et al. Cognitive function in peripheral autonomic disorders. PLoS One. 2014; 9(1):e85020. [PubMed: 24465471]

79. Gibbons CH, Centi J, Vernino S, Freeman R. Autoimmune autonomic ganglionopathy with reversible cognitive impairment. Arch Neurol. 2012; 69(4):461-6. [PubMed: 22158721]

80••. Gaspar JM, Baptista FI, Macedo MP, Ambrosio AF. Inside the diabetic brain: role of different players involved in cognitive decline. ACS Chem Neurosci. 2016; 7(2):131-42. This manuscript provides an in depth review of the current known pathways that can lead to impairment in cognition in the diabetic brain. [PubMed: 26667832]

81. Datusalia AK, Sharma SS. NF-kappaB inhibition resolves cognitive deficits in experimental type 2 diabetes mellitus through CREB and Glutamate/GABA neurotransmitters pathway. Curr Neurovasc Res. 2016; 13(1):22-32. [PubMed: 26517200]

82. Valente T, Gella A, Fernandez-Busquets X, Unzeta M, Durany N. Immunohistochemical analysis of human brain suggests pathological synergism of Alzheimer's disease and diabetes mellitus. Neurobiol Dis. 2010; 37(1):67-76. [PubMed: 19778613]

83. Puig KL, Floden AM, Adhikari R, Golovko MY, Combs CK. Amyloid precursor protein and proinflammatory changes are regulated in brain and adipose tissue in a murine model of high fat diet-induced obesity. PLoS One. 2012; 7(1):e30378. [PubMed: 22276186]

84. Dinel AL, Andre C, Aubert A, Ferreira G, Laye S, Castanon N. Cognitive and emotional alterations are related to hippocampal inflammation in a mouse model of metabolic syndrome. PLoS One. 2011; 6(9):e24325. [PubMed: 21949705]

85. Tomlinson DR, Gardiner NJ. Glucose neurotoxicity. Nat Rev Neurosci. 2008; 9(1):36-45. [PubMed: 18094705]

86. Kuhad A, Bishnoi M, Tiwari V, Chopra K. Suppression of NF-kappabeta signaling pathway by tocotrienol can prevent diabetes associated cognitive deficits. Pharmacol Biochem Behav. 2009; 92(2):251-9. [PubMed: 19138703]

87. Wang J, Li G, Wang Z, Zhang X, Yao L, Wang F, et al. High glucose-induced expression of inflammatory cytokines and reactive oxygen species in cultured astrocytes. Neuroscience. 2012; 202:58-68. DOI: 10.1016/j.neuroscience.2011.11.062 [PubMed: 22178606]

88. Sima AA. Encephalopathies: the emerging diabetic complications. Acta Diabetol. 2010; 47(4): 279-93. [PubMed: 20798963]

89. Fiatarone Singh MA, Gates N, Saigal N, Wilson GC, Meiklejohn J, Brodaty H, et al. The Study of Mental and Resistance Training (SMART) study-resistance training and/or cognitive training in mild cognitive impairment: a randomized, double-blind, double-sham controlled trial. J Am Med Dir Assoc. 2014; 15(12):873-80. [PubMed: 25444575] 
90. Guimaraes FC, Amorim PR, Dos Reis FF, Bonoto RT, de Oliveira WC, Moura TA, et al. Physical activity and better medication compliance improve mini-mental state examination scores in the elderly. Dement Geriatr Cogn Disord. 2015; 39(1-2):25-31. [PubMed: 25300502]

91. Gates N, Fiatarone Singh MA, Sachdev PS, Valenzuela M. The effect of exercise training on cognitive function in older adults with mild cognitive impairment: a meta-analysis of randomized controlled trials. Am J Geriatr Psychiatry. 2013; 21(11):1086-97. [PubMed: 23831175]

92. Fiocco AJ, Scarcello S, Marzolini S, Chan A, Oh P, Proulx G, et al. The effects of an exercise and lifestyle intervention program on cardiovascular, metabolic factors and cognitive performance in middle-aged adults with type II diabetes: a pilot study. Can J Diabetes. 2013; 37(4):214-9. [PubMed: 24070883]

93. Baker LD, Frank LL, Foster-Schubert K, Green PS, Wilkinson CW, McTiernan A, et al. Aerobic exercise improves cognition for older adults with glucose intolerance, a risk factor for Alzheimer's disease. J Alzheimers Dis. 2010; 22(2):569-79. [PubMed: 20847403]

94. Watson GS, Reger MA, Baker LD, McNeely MJ, Fujimoto WY, Kahn SE, et al. Effects of exercise and nutrition on memory in Japanese Americans with impaired glucose tolerance. Diabetes Care. 2006; 29(1):135-6. [PubMed: 16373910]

95. Ang L, Jaiswal M, Martin C, Pop-Busui R. Glucose control and diabetic neuropathy: lessons from recent large clinical trials. Curr Diab Rep. 2014; 14(9):528-0528. [PubMed: 25139473]

96. Rdzak GM, Abdelghany O. Does insulin therapy for type 1 diabetes mellitus protect against Alzheimer's disease? Pharmacotherapy. 2014; 34(12):1317-23. [PubMed: 25280207]

97. Liu W, Li G, Holscher C, Li L. Neuroprotective effects of geniposide on Alzheimer's disease pathology. Rev Neurosci. 2015; 26(4):371-83. [PubMed: 25879319]

98. Kosaraju J, Murthy V, Khatwal RB, Dubala A, Chinni S, Muthureddy Nataraj SK, et al. Vildagliptin: an anti-diabetes agent ameliorates cognitive deficits and pathology observed in streptozotocin-induced Alzheimer's disease. J Pharm Pharmacol. 2013; 65(12):1773-84. [PubMed: 24117480]

99. McClean PL, Holscher C. Lixisenatide, a drug developed to treat type 2 diabetes, shows neuroprotective effects in a mouse model of Alzheimer's disease. Neuropharmacology. 2014; 86:241-58. DOI: 10.1016/j.neuropharm.2014.07.015 [PubMed: 25107586]

100. McClean PL, Parthsarathy V, Faivre E, Holscher C. The diabetes drug liraglutide prevents degenerative processes in a mouse model of Alzheimer's disease. J Neurosci. 2011; 31(17):658794. [PubMed: 21525299]

101. Pipatpiboon N, Pintana H, Pratchayasakul W, Chattipakorn N, Chattipakorn SC. DPP4-inhibitor improves neuronal insulin receptor function, brain mitochondrial function and cognitive function in rats with insulin resistance induced by high-fat diet consumption. Eur J Neurosci. 2013; 37(5): 839-49. [PubMed: 23240760]

102. Pintana H, Apaijai N, Chattipakorn N, Chattipakorn SC. DPP-4 inhibitors improve cognition and brain mitochondrial function of insulin-resistant rats. J Endocrinol. 2013; 218(1):1-11. [PubMed: 23591914]

103. Kuhad A, Chopra K. Effect of sesamol on diabetes-associated cognitive decline in rats. Exp Brain Res. 2008; 185(3):411-20. [PubMed: 17955223]

104. Tuzcu M, Baydas G. Effect of melatonin and vitamin E on diabetes-induced learning and memory impairment in rats. Eur J Pharmacol. 2006; 537(1-3):106-10. [PubMed: 16626697]

105. Kuhad A, Chopra K. Curcumin attenuates diabetic encephalopathy in rats: behavioral and biochemical evidences. Eur J Pharmacol. 2007; 576(1-3):34-42. [PubMed: 17822693] 


\section{Insulin Sensitive Synaptic Signaling}

(A)

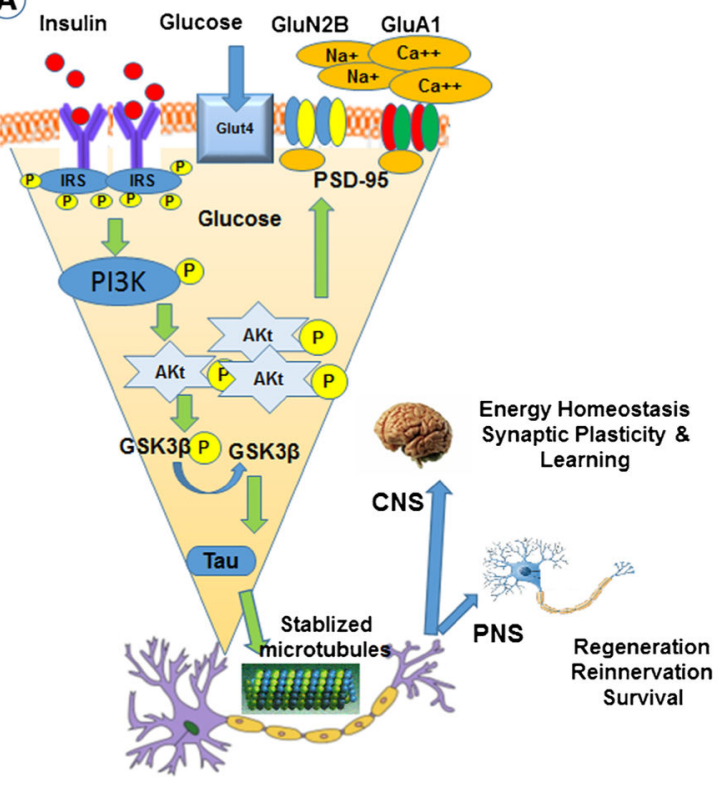

Insulin Resistance Synaptic Signaling

(B)

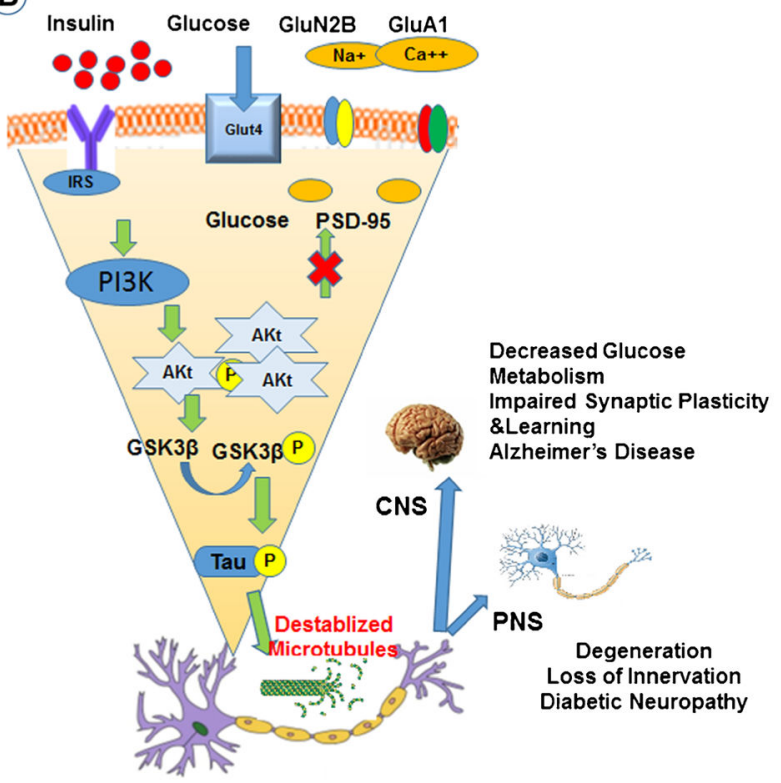

Fig. 1.

Neuronal insulin signaling in synaptic plasticity and memory in normal and diabetic brain. Schematic outline of neuronal insulin signaling in the normal brain (a) and in the diabetic brain (b). In physiological conditions, insulin binding to its receptor at the synapse triggers phosphorylation of insulin receptor substrate-1(IRS-1). This results in phosphoinositide 3kinase (PI3K) activation, Akt phosphorylation, phosphorylation of GluA1, and increased presence of GluN2B at synapses. These events favor synapse formation and memory function. In the diabetic brain, insulin resistance decreases levels of insulin receptors and reduces insulin signaling. This leads to decreased levels of GluN2B and GluA1 phosphorylation at synapses, ultimately leading to impaired synaptic plasticity and memory. The reduction in brain insulin signaling increases GSK-3b activity which increases abnormal tau phosphorylation 
Insulin Sensitive Mitochondrial Signaling

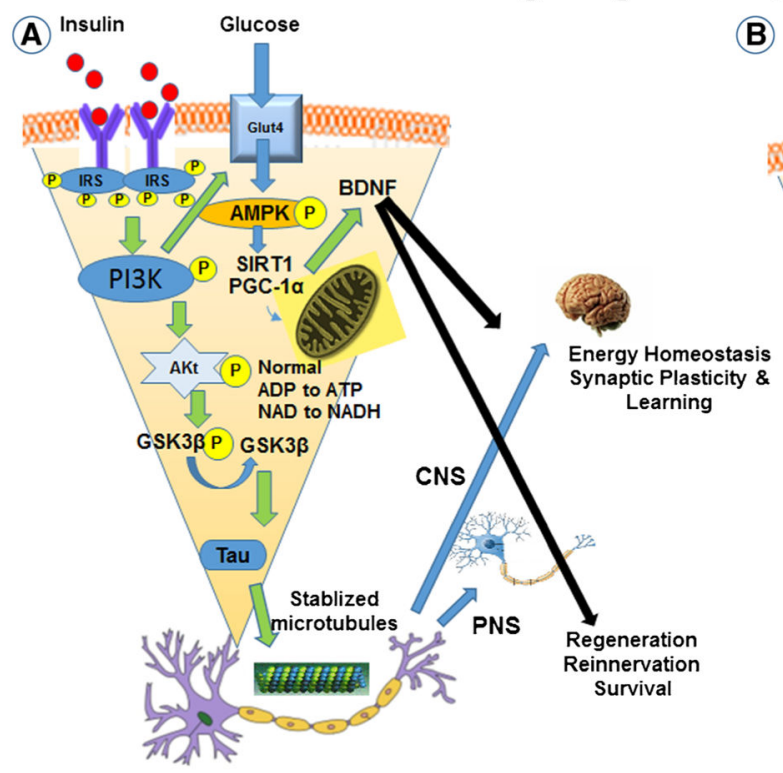

B)
Insulin Resistance Mitochondrial Signaling

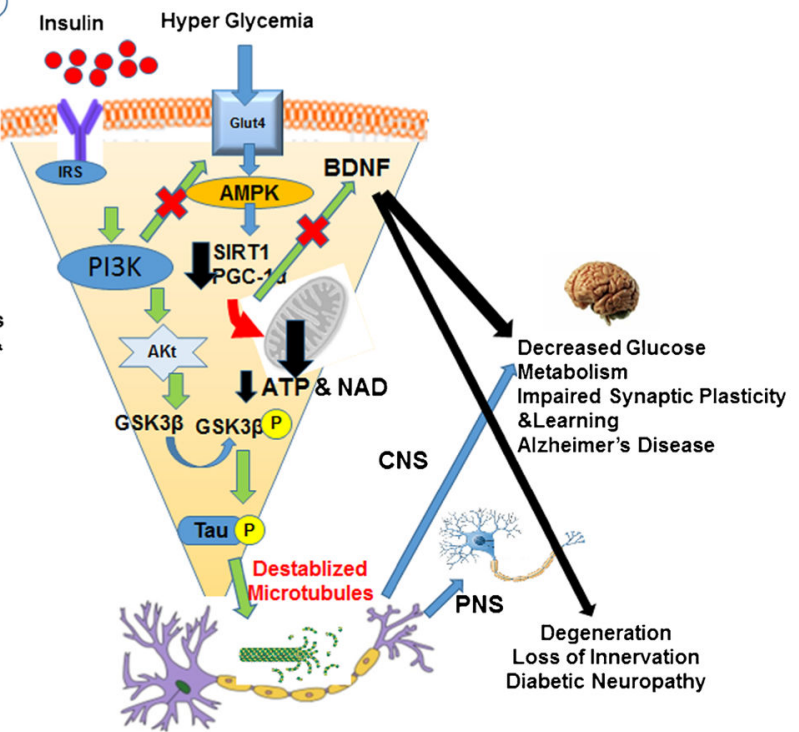

Fig. 2.

Mechanistic association of insulin signaling with mitochondrial function in normal and diabetic brain. Schematic outline of neuronal insulin signaling in the normal brain (a) and in the diabetic brain (b). In physiological conditions, insulin binding to its receptor at the synapse triggers phosphorylation of IRSs, PI3K activation, Akt phosphorylation, inhibits the transcriptional factor FOXO1, and promotes the AMPK-SIRT1-PGC-1a mediated Mt metabolic pathway. In the diabetic brain, insulin resistance and impaired insulin signaling reduces signaling in these pathways and decreases the stability of Mt electron transport proteins thereby increasing oxidative stress. Insulin resistance impairs the electron transport chain, reducing ATP and $\mathrm{NAD}^{+}$generation, and inhibits activation of the $\mathrm{NAD}^{+}$-dependent deacetylase SIRT1. Inactivation of SIRT1 further reduces Mt function and repair. As in Fig. 1 , the reduction in brain insulin signaling also increases GSK-3b activity that increases abnormal tau phosphorylation 